\title{
Research Paper Study on modeling and forecasting of tobacco production in India
}

\section{PREMA BORKAR AND V. M. BODADE}

See end of the paper for authors' affiliations

\section{Correspondence to :}

\section{PREMA BORKAR}

Gokhale Institute of Politics and Economics, PUNE (M.S.) INDIA

\section{Paper History :}

Received : 16.01.2017;

Revised : 17.07.2017;

Accepted : 29.07.2017
Abstract : The paper describes an empirical study of modeling and forecasting time series data of tobacco production in India. Yearly tobacco production data for the period of 1950-1951 to 2014-2015 of India were analyzed by time-series methods. Autocorrelation and partial autocorrelation functions were calculated for the data. The Box Jenkins ARIMA methodology has been used for forecasting. The diagnostic checking has shown that $\operatorname{ARIMA}(1,1,1)$ is appropriate. The forecasts from 2015-2016 to 2019-2020 are calculated based on the selected model. The forecasting power of autoregressive integrated moving average model was used to forecast tobacco production for five leading years. These forecasts would be helpful for the policy makers to foresee ahead of time the future requirements of tobacco production, import and/or export and adopt appropriate measures in this regard.

KEY WordS : ACF - Autocorrelation function, ARIMA - Autoregressive integrated moving average, Forecast, PACF - Partial autocorrelation function, Tobacco

How To Cite This Paper : Borkar, Prema and Bodade, V.M. (2017). Study on modeling and forecasting of tobacco production in India. Internat. Res. J. Agric. Eco. \& Stat., 8 (2) : 281-286, DOI : 10.15740/HAS/IRJAES/ 8.2/281-286. 